\title{
Identification of SSR \& ISSR Markers Associated to Off-Type Somaclonal Variants in Micro-Propagated Banana
}

\author{
Shubhankar Tarafdar ${ }^{1}$, K. Subramanyam Gupta ${ }^{2}$, Shubha Banerjee ${ }^{1}$ and \\ D. Shailja ${ }^{4}$ \\ ${ }^{1}$ Adithya Biotech Lab \& Research Pvt. Ltd. Raipur, C.G, India \\ ${ }^{2}$ Shreenidhi Institute of Science \& Technology, Hyderabad, Telangana, India \\ ${ }^{3}$ Gokaraju Rangaraju Institute of Technology, JNTU, Hyderabad, Telangana, India
}

\begin{abstract}
Occurrence of somaclonal variants is a common and persistent feature of TC industry. The somaclonal variants are important source of genetic variation in asexually propagated plant species and thus are considered as a potential mean for development of new crop variety. Present study showed identification of DNA markers (SSR) linked to off-type traits in micropropagated banana. For which three category of off-type plants $(O 1, O 2 \&$ O3) were characterized and used for DNA isolation. A total of 150 SSR and ISSR markers were screened, all one hundred fifty SSR markers showed monomorphic banding pattern. Out of these markers only nine of them were screened and selected for CAPS marking, out of which only one marker MaCIRI12 showed slight polymorphism. The PCR product of the same marker was then digested using restriction enzyme, and only Pst I showed polymorphic bands between off-types and normal plants.Digested product of MaCIR112 and some undigested product of off-types were then sequenced and SCAR marker was developed. Newly developed marker was then validated further for confirmation of polymorphic banding pattern between off-type \& normal plants.
\end{abstract}

Abbreviation: CTAB-Hexadecyl trimethyl ammonium Bromide; ISSR-inter-simple sequence repeat; SSR-simple sequence repeat, $\mathbf{T C}$ - Tissue Culture.

Keywords: Banana, DNA Marker, Micropropagation, Somaclonal Variation, SCAR, SSR

\section{Introduction}

Banana is most widely grown fruit crop in tropical and subtropical regions [1] and micro-propagated banana planting material offers several advantages over vegetative propagation. Somaclonal variations, either genetic or epigenetic in nature, have been considered an integral part of in-vitro regeneration process. Somaclonal variants are an important source of genetic variation especially in vegetatively propagated plants and have been used as a tool for plant improvement as well as development of new varieties [2]; [3]; [4]. Important features for which in vitro propagation are opted is its enormous multiplicative capacity in a relatively short span of time, production of healthy and disease free plants and its ability to generate propagules through out the year [5]. These variations are often undesirable in a TC industry where the main aim is production of 'true to type' plants. Characterization of off-type variants for traits superior to mother plants in terms of yield, fruit quality, resistance to biotic or abiotic stresses and higher regeneration efficiency in TC media might lead to development of new cultivar. Dwarf Cavendish, Grand Naine Israel, Lancefield, Chinese Cavendish are some of the proven examples where somaclonal variants/mutants have been characterized, selected and released as new variety in different parts of the world. However, some of the somaclonal variants also show characteristic feature inferior to the mother plants and causes heavy yield and economic loss to farmers as well as TC industry. It is therefore important to characterize, select and assess the somaclonal variants for presence of elite and offtypes traits observed during in-vitro regeneration or in farmers' field. Morphological description, physiological supervision, karyotyping, biochemical estimations and field assessment have been used conventionally to describe and characterize such somaclonal variants. Since most of these traits are governed by many genes having additive or environment interactive effects, they remain highly subjective and difficult to identify. Recently molecular characterization and identification techniques are being used for efficient and effective management of plant genetic resources. Genetic uniformity of in vitro raised plants also a prerequisite for production of quality planting material of banana [6]. Somaclonal variation is now a days used as tool for development of new varities having exciting traits like disease resistance, dwarf plants, high yielding plants etc. Like wise researchers obtained Somaclonal variant CIEN BTA-03 resistant to yellow Sigatoka from a susceptible banana clone (Williams clone), by increasing the production of adventitious buds using 6Belcilaminopurine at high concentrations. This somaclone has exhibited yellow Sigatoka resistance in the field for five consecutive years of asexual reproduction [7].According to [8], the mechanism of somaclonal variation involves extensive genomic flux or altered methylation patterns and those results in inheritable traits in progeny. 
Moreover, epigenetic or reversible factors and traits are also involved, hence making it more complex [9]. Somaclonal variation arising from in-vitro production of plantlets is associated with DNA novel and heritable phenotypic variation which could be epigenetic or genetic[10].The present day molecular markers have complemented traditional methods to detect genetic variants, monitor genetic fidelity and varietal development of asexually propagated plants. Thus, DNA markers based characterization of somaclonal variants showing discrete elite or off-type characters followed by identification of markers associated to superior traits (if any) would be extremely beneficial. Identification of DNA markers linked to desirable quality traits or off-type traits in cash crops like banana will have significant role in improving the existing plant variety and subsequent development of newer cultivars.Identification of such DNA based markers would ultimately help to identify offtype plants in earlier stages of production and may be eliminated during the process.

\subsection{Plant material}

\section{Materials \& Method}

Leaf sample of banana plant used in this study were acquired from Adithya Biotech Lab and Research Pvt Ltd Raipur. Fresh young leaves from all plants were collected for DNA extraction.

\subsection{DNA extraction}

Genomic DNA was isolated according to a modified CTAB method (Zhu et al., 2010) ${ }^{12}$. The concentration and quality of the obtained genomic DNA samples were estimated by measuring O.D. at 260/280 $\mathrm{nm}$ in UV spectrophotometer. Finally, all the genomic DNA samples were diluted to a final concentration of $40 \mathrm{ng} / \mu \mathrm{l}$ with $1 \mathrm{X}$ TE buffer (10mM Tris-HCL; $\mathrm{pH} 8.0 ; 1 \mathrm{mM}$ EDTA). Intactness of genomic DNA was checked by agarose gel electrophoresis. DNA samples were stored at $-20^{\circ} \mathrm{C}$ for further use.

\subsection{SSR-PCR amplification and agarose gel electrophoresis analysis}

SSR amplification was conducted in a $20 \mu$ l volume containing $40 \mathrm{ng}$ of genomic DNA, $10 \mathrm{X}$ buffer, $1 \mathrm{U}$ Taq DNA polymerase, $1.5 \mathrm{mM} \mathrm{MgCl}_{2}, 2.5 \mathrm{mM}$ dNTPs, 3 pmol forward and $3 \mathrm{pmol}$ reverse primer. The PCR protocol consisted of an initial denaturation at $94^{\circ} \mathrm{C}$ for $4 \mathrm{~min}$, followed by 35 cycles of $94^{\circ} \mathrm{C}$ for $20 \mathrm{sec}$, annealing for $30 \mathrm{sec}$ at $56^{\circ} \mathrm{C}, 72^{\circ} \mathrm{C}$ for $1 \mathrm{~min}$ and final extension step of $72^{\circ} \mathrm{C}$ for $7 \mathrm{~min}$. The amplification reaction was carried out in thermo cycler (Applied Biosystems). The PCR products were analysed on $2 \%$ agarose gel along with 100bp molecular weight marker and photographed under UV light using Bio-Rad gel documentation system.

\subsection{Restriction Digestion}

PCR product of Primer MaCIR112 was digested with the five restriction enzymes i.e. HaeIII, BamH1,PstI, Sau3AI, HindIII at $37{ }^{\circ} \mathrm{C}$ for $1 \mathrm{hr}$.The digested products were analysed on $2 \%$ agarose gel along with 100bp molecular weight marker and photographed under UV light using Bio-Rad gel documentation system.

\subsection{Validation of new SCAR Marker}

PCR amplification was conducted in a $20 \mu$ l volume containing $40 \mathrm{ng}$ of genomic DNA, $10 \mathrm{X}$ buffer, $1 \mathrm{U}$ Taq DNA polymerase, $1.5 \mathrm{mM} \mathrm{MgCl} 2,2.5 \mathrm{mM}$ dNTPs, $3 \mathrm{pmol}$ forward and $3 \mathrm{pmol}$ reverse primer. The PCR protocol consisted of an initial denaturation at $94^{\circ} \mathrm{C}$ for $3 \mathrm{~min}$, followed by 35 cycles of $94^{\circ} \mathrm{C}$ for $20 \mathrm{sec}$, annealing for $30 \mathrm{sec}$ at $55^{\circ} \mathrm{C}, 72^{\circ} \mathrm{C}$ for $1 \mathrm{~min}$ and final extension step of $72^{\circ} \mathrm{C}$ for $5 \mathrm{~min}$. The amplification reaction was carried out in thermo cycler (Applied Biosystems). The PCR products were analysed on 2\% agarose gel along with 100bp molecular weight marker and photographed under UV light using Bio-Rad gel documentation system.

\subsection{SSR fragments analysis by agarose gel electrophoresis \\ III. Result \& Discussion}

Microsatellite markers were used for identification of Banana offtype plant (Figure a,b,c,d). 150 SSR\& ISSR primer were initially screened identification of Banana off type plant. All of the primer pairs had good amplification. Out of 150 microsatellite primers, 1pair i.e.PmMacir112,(Forward5' GTTCGGCT GGAGG TAGTT3' Reverse5'AAGAACACGAAGGCAGG 3') were scorable on agarose gel and showed polymorphism between normal \& off type Banana plant.

\subsection{Restriction digestion fragments analysis by agarose gel electrophoresis}

Out of 5 restriction enzyme only PstI enzyme showed polymorphism for elite and off types Banana plants. Digested product of elite and off type plant were sent for sequencing for SCAR marker development.

\subsection{SCAR marker fragments analysis by agarose gel electrophoresis}

Newly developed SCAR marker P BOT (Forward 5' TCGGAAAGAGCCACATATC 3'Reverse

5' GAAGATGCGTCCTGGTTG 3') were scorable on agarose gel and showed polymorphism between normal \& off type Banana plant. Normal plant showed $330 \mathrm{bp}$ band and off type plant show $310 \mathrm{bp}$.By using this marker we can easily identify off type banana Plant. 


\section{Figures and Tables}

\section{Figure 1}

$\mathrm{MaCIR} 112$

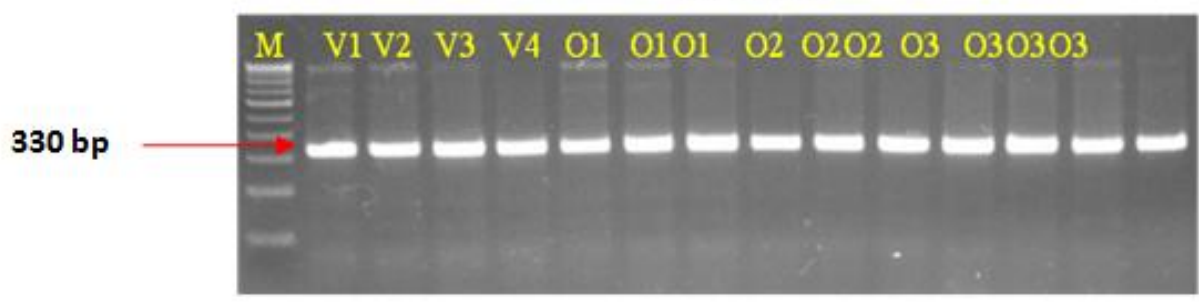

Fig 1.Marker MaCIR112 showed slightly polymorphism between Off-type \& Vigour categories in terms of base pair of all four clones. Lane 1- represents 100bp Marker (100-1000bp), lane 2-5-represent normal plants, lane 6-8-represent off type plant1, lane 9-11-represents off type plant2

Figure 2

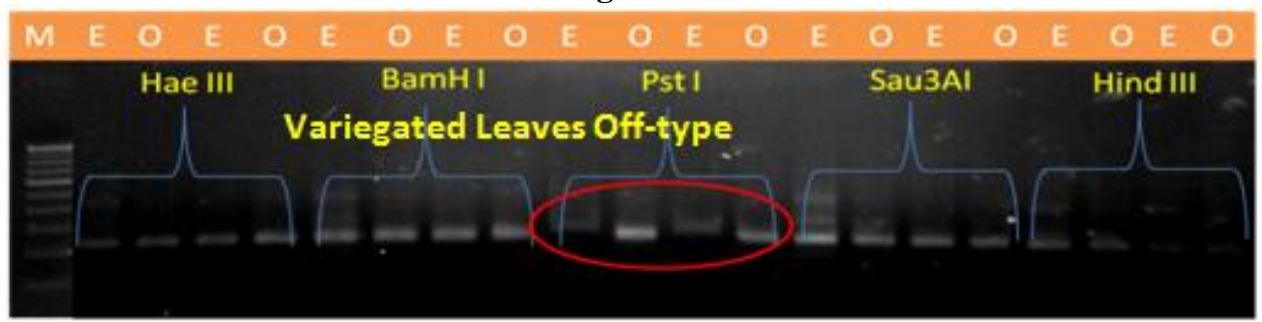

Fig 2. PCR product of MaCIR112 was digested with the five restriction enzymes i.e Hae III, BamH I, Pst I, SauAI, Hind III. Out of these five restriction enzymes only PstI enzyme showed polymorphism for elite and off types.

\section{Figure 3}

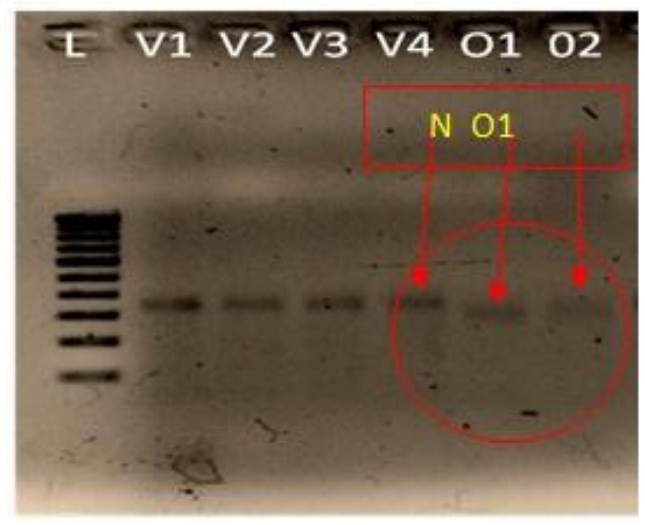

Fig 3. Amplification results of SCAR marker P BOT for distinguish normal and off type banana plants. Lane 1- represent 100bp ladder (100-1000bp), Lanes 2-5-represent normal plants(amplification size 330bp), Lanes 6-7- represent off type plants(amplification size 310bp). After PCR it was observed that the elite and offtype plants of GA clone showed different banding pattern (polymorphism) while rest clones showed monomorphic banding pattern. 


\section{Figure 4}

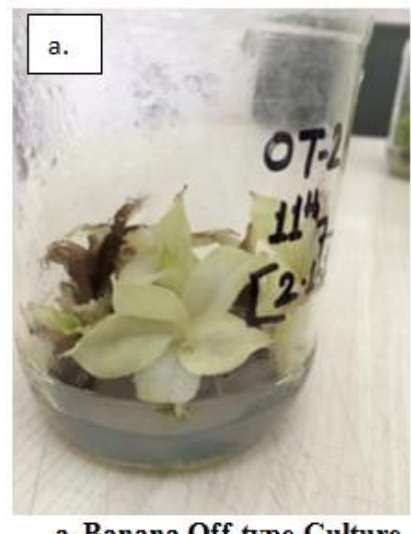

a. Banana Off-type Culture

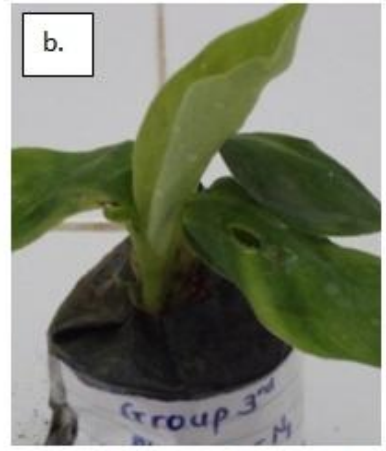

b. Off-type banana deformed Leaves
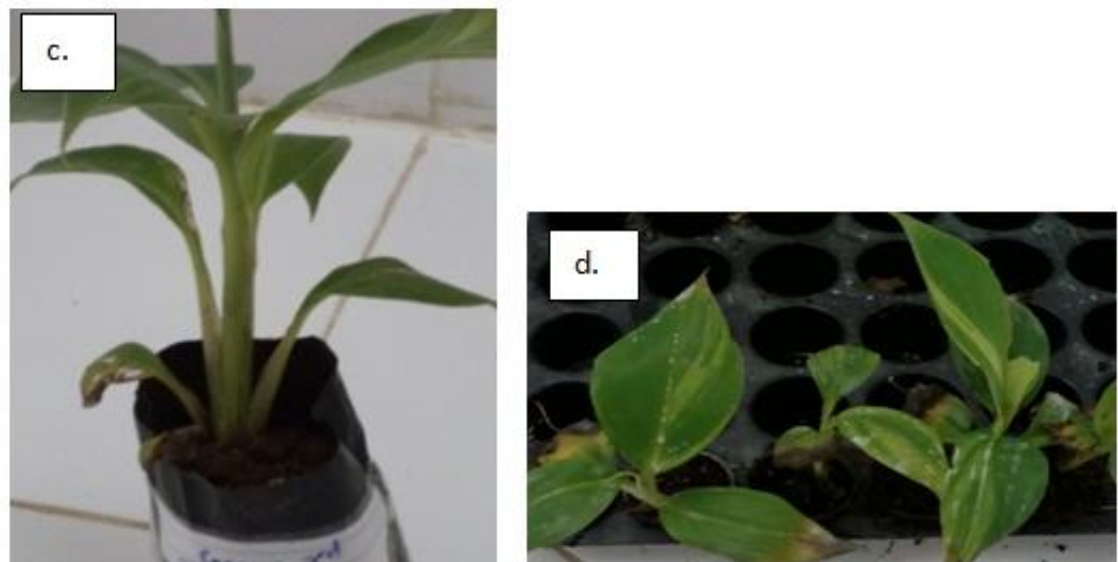

c. Off-type Banana (O3) Deformed d. Off-type Banana (O1) Variegated Leaves pseudostem

\section{Conclusion}

In tissue culture industries somaclonal variation id not a desirable thing, as it affects the overall quality of the planting material. Many variants are epigenetic but still needed to be eliminated in early stages to minimize the after effect of it in the field condition. Variations may decline in productivity of a particular plant in the field, ultimately resulting in heavy loss in terms of economics to the end user. Somaclonal variation being random and non-directional, is unpredictable, not controllable and poses the disadvantage of giving rise to very low number of useful variants [11]. A total of 150 SSR and ISSR markers were screened, all one hundred fifty SSR markers showed monomorphic band. Out of 150; makers nine were selected for the CAPS marker technology. In these nine markers only MaCIR112 showed slight polymorphism between normal and offtypes. On the basis of field performance of the clones only normal and offtype (deformed leaves and deformed pseudostem) plants were used for the identification of associated marker study. PCR product of MaCIR112 was digested with the four restriction enzymes and only with PstI enzyme showed polymorphism for normal and offtypes. Digested products of normal and undigested product of offtype plant were sent for sequencing for SCAR marker development. After Sequencing markers were generated with batch primer 3.0 and used for genotyping. Newly developed marker was also showed polymorphism between normal and offtype clones

\section{Acknowledgement}

Authors are grateful to Mr. Shailendra Jain \& Ms. Shubhika Jain (Director, ABLR) for their continuous support during the research work and Dr. Pulak Das for his contribution and guidance.

\section{Reference}

[1] Kalloo, G.2002. Banana and plantation research in India - a perspective. GlobalConf. on Banana and Plantain, October 28-31, Bangalore, India.Abstracts.

[2] C.A. Cullis, "The Molecular Biology of Plant Cells and Cultures", Plant Biotechnology, Pergamon Press, pp. 19-32, 1992.

[3] Karp A (1993). Are your plants normal? Genetic instability in regenerated and transgenic plants. Agro-Food-Industry Hi-Tech May/ June 7-12

[4] Cassells AC, Joyce SM, Curry RF, McCarthy TF (1999) Detection of economic variability in micropropagation. In: Altman A., Ziv M, Izhar, S (Eds), Plant Biotechnology and In vitro Biology in the 21st century, Kluwer Academic Publishers, The Netherlands

[5] Dhawan V, Bhojwani SS. (1986) Micropropagation in crop plants. Glimpses Plant Res., 7: 1- 75. 
[6] G.R. Rout*, S. K. Senapati, S. Aparajita, S.K. Palai, (2009) Studies on genetic identification and genetic fidelity of cultivated banana using ISSR markersPlant Omics Journal Southern Cross Journals@2009 2(6):250-258 (2009) www.pomics.com ISSN: 1836-3644

[7] D.C.V. Maria, E.D. Garcia, “Analysis of a Musa spp. somaclonal variant resistant to yellow sigatoka”, Plant Mol Biol Rep, Vol. 18, pp. 23-31, 2000 .

[8] Scowcroft, W.R., S.A. Ryan, R.I.S. Brettel and P.J. Larkin. 1985. Biotechnology in International Agricultural Research, IRRI, Manila.Pp:99-109.

[9] Kaeppler, S.M., H. Kaeppler, Y. Rhee. 2000:Epigenetic aspects of somaclonal variation in plants. Plant Mol Bio Rep 43:179-188.

[10] Lukens, L.N., S. Zhan. 2007: The plant genome's methylation status and response to stress:implications for plant improvement. CurrOpinPlant Biol 10:317-322.

[11] Tang CY (2005) Somaclonal Variation: a tool for the improvement of Cavendish banana cultivars. Acta Horticulture 692, 61-65

[12] YF Zhu, J Hu, Y Zhang, YJ Guan, XX Huang, SJ Zhu Transferability of SSR markers derived from cowpea (Vigna unguiculata L. Walp) in variety identification. Seed Sci Technol. 38 (2010) 730-740. 